\title{
DIGITALCOMMONS
}

—@WAYNESTATE-

Human Biology

Volume 84 | Issue 2

Article 3

2012

\section{Human Pelvis and Long Bones Reveal Differential Preservation of Ancient Population History and Migration Out of Africa}

Lia Betti

Department of Anthropology, School of Anthropology and Conservation, University of Kent, Canterbury, UK, lb322@kent.ac.uk

Noreen Von Cramon-Taubadel

Department of Anthropology, School of Anthropology and Conservation, University of Kent, Canterbury, UK, N.VonCramon@kent.ac.uk

Stephen J. Lycett

Department of Anthropology, School of Anthropology and Conservation, University of Kent, Canterbury, UK, S.J.Lycett@kent.ac.uk

Follow this and additional works at: http:/ / digitalcommons.wayne.edu/humbiol

\section{Recommended Citation}

Betti, Lia; Von Cramon-Taubadel, Noreen; and Lycett, Stephen J. (2012) "Human Pelvis and Long Bones Reveal Differential Preservation of Ancient Population History and Migration Out of Africa," Human Biology: Vol. 84: Iss. 2, Article 3.

Available at: http://digitalcommons.wayne.edu/humbiol/vol84/iss2/3 


\title{
Human Pelvis and Long Bones Reveal Differential Preservation of Ancient Population History and Migration Out of Africa
}

\begin{abstract}
One of the main events in the history of our species has been our expansion out of Africa. A clear signature of this expansion has been found on global patterns of neutral genetic variation, whereby a serial founder effect accompanied the colonization of new regions, in turn creating a within-population decrease in neutral genetic diversity with increasing distance from Africa. This same distinctive pattern has also been described for cranial and dental morphological variation in human populations distributed across the globe. Here, we used a data set of postcranial linear measurements for 30 globally distributed human populations, and a climatic data set of minimum annual temperature, maximum annual temperature, and precipitation in order to separate for the first time the relative effect of neutral demographic processes and climatic selection on four long (limb) bones (femur, tibia, radius, and humerus) versus the pelvic bones of the human appendicular skeleton. We implemented a stepwise regression procedure in which phenotypic variance is assumed to be affected by the iterative founder events that accompanied human expansion from Africa, as well as by climate. This model included, as independent factors, geographic distance from central Africa, the three climatic variables, and all possible interactions between the three climatic variables. We excluded all nonsignificant factors by backward stepwise elimination with the aim of identifying the minimal model significantly explaining variation in the phenotypic data. Our results indicate a sharp difference in the way the pelvis and the limb bones reflect the neutral signature of the out-of-Africa expansion. Consistent with previous analyses of the cranium and dentition, pelvic shape variation shows a significant within-population decrease with increasing distance from Africa. However, no such pattern could be found in the long bones. Rather, in the case of both the tibia and the femur, a significant relationship between population-level variance and minimum temperature was demonstrated. Hence, in the case of these limb bones, it is probable that the effects of climatic selection have obliterated the demographic signature of human dispersal from Africa. Our finding that pelvic variation exhibits the neutral effects of demographic history suggests that consideration of this skeletal element might be used to shed light on factors of human population history, just as the cranium has done.
\end{abstract}

\section{Keywords}

Serial Founder Effect, Out Of Africa, Anatomically Modern Humans, Pelvis

\section{Cover Page Footnote}

We are grateful to Brendon Billings of the Medical School of the University of Witwatersrand and Dr. Ogeto Mwebi of the National Museum of Kenya for allowing access to collections and general assistance. We are also especially grateful to Dr. Benjamin Auerbach for generously making his data freely available. We thank Franz Manni and three anonymous reviewers for constructive comments. This study was funded by Sigma Xi, The Wenner-Gren Foundation for Anthropological Research, and a University of Kent Research Scholarship. 


\title{
Human Pelvis and Long Bones Reveal Differential Preservation of Ancient Population History and Migration Out of Africa
}

\author{
LIA BETTI, ${ }^{1} *$ NOREEN VON CRAMON-TAUBADEL, ${ }^{1}$ AND STEPHEN J. LYCETT $^{1}$
}

Abstract One of the main events in the history of our species has been our
expansion out of Africa. A clear signature of this expansion has been found
on global patterns of neutral genetic variation, whereby a serial founder
effect accompanied the colonization of new regions, in turn creating a
within-population decrease in neutral genetic diversity with increasing
distance from Africa. This same distinctive pattern has also been described
for cranial and dental morphological variation in human populations distrib-
uted across the globe. Here, we used a data set of postcranial linear
measurements for 30 globally distributed human populations, and a climatic
data set of minimum annual temperature, maximum annual temperature, and
precipitation in order to separate for the first time the relative effect of
neutral demographic processes and climatic selection on four long (limb)
bones (femur, tibia, radius, and humerus) versus the pelvic bones of the
human appendicular skeleton. We implemented a stepwise regression
procedure in which phenotypic variance is assumed to be affected by the
iterative founder events that accompanied human expansion from Africa, as
well as by climate. This model included, as independent factors, geographic
distance from central Africa, the three climatic variables, and all possible
interactions between the three climatic variables. We excluded all nonsig-
nificant factors by backward stepwise elimination with the aim of identifying
the minimal model significantly explaining variation in the phenotypic data.
Our results indicate a sharp difference in the way the pelvis and the limb
bones reflect the neutral signature of the out-of-Africa expansion. Consistent
with previous analyses of the cranium and dentition, pelvic shape variation
shows a significant within-population decrease with increasing distance from
Africa. However, no such pattern could be found in the long bones. Rather,
in the case of both the tibia and the femur, a significant relationship between
population-level variance and minimum temperature was demonstrated.
Hence, in the case of these limb bones, it is probable that the effects of
climatic selection have obliterated the demographic signature of human

${ }^{1}$ Department of Anthropology, School of Anthropology and Conservation, University of Kent, Canterbury, UK.

*Correspondence to: Lia Betti, Department of Anthropology, School of Anthropology and Conservation, University of Kent, Canterbury, UK. E-mail: 1b322@kent.ac.uk.

Human Biology, April 2012, v. 84, no. 2, pp. 139-152 .

Copyright @ 2012 Wayne State University Press, Detroit, Michigan 48201-1309.

KEY WORDS: SERIAL FOUNDER EFFECT, OUT OF AFRICA, ANATOMICALLY MODERN HUMANS, PELVIS 
dispersal from Africa. Our finding that pelvic variation exhibits the neutral effects of demographic history suggests that consideration of this skeletal element might be used to shed light on factors of human population history, just as the cranium has done.

In recent years, the application of a population genetic approach has revealed that neutral evolutionary processes (i.e., drift and migration) can leave a strong signature on human phenotypic traits (e.g., Betti et al., 2009, 2010; Harvati and Weaver 2006a, 2006b; Manica et al. 2007; Relethford 1994, 2002, 2004; Roseman 2004; Roseman and Weaver 2004, 2007; Smith 2009, 2011; Strauss and Hubbe 2010; von Cramon-Taubadel and Lycett 2008; von Cramon-Taubadel 2009a, 2009b, 2011; von Cramon-Taubadel and Weaver 2009). Cranial shape variation in different human populations, in particular, tends to reflect the underlying neutral genetic pattern, to the point that cranial morphology can be used effectively to test for past demographic events, such as past migrations and the colonization of new regions (e.g., González-José et al. 2001, 2002, 2007; Hubbe et al. 2010, 2011; Manica et al. 2007; Pinhasi and von Cramon-Taubadel 2009; von Cramon-Taubadel and Pinhasi 2011).

One of the main events in the history of our species (Homo sapiens) has been the expansion out of the African continent, where the human species originated around 200,000 years ago, and the colonization of other continents occurred from at least 60,000 years ago (Cann et al. 1987; Ingman et al. 2000; Thomson et al. 2000). A very clear signature of the Out-of-Africa (OoA) expansion has been found on global patterns of neutral genetic variation, whereby an iterative founder effect that accompanied the colonization of new regions by peripheral populations generated a gradual decrease in genetic diversity with increasing distance from the African point(s) of origin (Liu et al. 2006; Prugnolle et al. 2005; Ramachandran et al. 2005). Notably, this genetic pattern is compatible with both single and multiple dispersals (e.g., Rasmussen et al. 2011) of populations from Africa, since the same basic relationship (i.e., between geographic distance from Africa and reduced within-group genetic variance) will be evinced regardless of how frequently any such dispersal(s) took place. Indeed, although recent genetic studies suggest that during this range expansion modern humans interbred with Neanderthals (H. neanderthalensis) and possibly other hominin species (Currat and Excoffier 2011; Green et al. 2010; Stoneking and Krause 2011), the limited amount of gene flow between these species, if any (Ghirotto et al. 2011a, 2011b; Hodgson et al. 2010), was evidently not enough to erase the OoA signature (Manica et al. 2007; Prugnolle et al. 2005; Ramachandran et al. 2005). Indeed, as Green et al. (2010: 721) put it, their analysis of the Neanderthal genome "continues to support the view that the vast majority of genetic variants that exist at appreciable frequencies outside Africa came from Africa with the spread of anatomically modern humans".

This same distinctive pattern has also been described for cranial and dental morphological variation, giving additional evidence that some skeletal traits vary according to a null model of neutral evolution (Betti et al. 2009; 
Hanihara 2008; Manica et al. 2007; von Cramon-Taubadel and Lycett 2008). The presence of a neutral signal in craniodental traits may be seen as largely unexpected, since many studies had previously focused on the effects of selective pressures and developmental plasticity in creating cranial shape variation (e.g., Beals 1972; Beals et al. 1983, 1984; Franciscus and Long 1991).

Climate, in particular, has always been considered a powerful factor in shaping skeletal morphology, especially in the case of the postcranium. Allen's (1877) and Bergmann's (1847) rules offer specific predictions on how body proportions should change under strong climatic selection. Following Allen's (1877) rule, animals living in cold climates tend to have relatively shorter extremities than similar species or subspecies in warmer climates, in order to reduce the dissipation of heat. It has been suggested that Allen's rule has affected human populations in this manner, with populations living in cold regions exhibiting relatively shorter limb bones in respect to overall stature, versus relatively longer limbs in warm (equatorial) climates (Holliday and Hilton 2010). Conversely, Bergmann's (1847) rule states that populations living in cold regions tend to have higher body mass (i.e., increased volume), which can be achieved by an increase in absolute size. In line with Bergmann's rule, it has previously been shown that Inuit and other arctic populations have a higher body mass, larger trunks and pelvic regions in respect to most populations living near the equator (Holliday 1997; Ruff 1993, 1994). In summary, Allen's rule may be considered a change in overall body shape in the absence of an increase or decrease in the mass (volume) of an individual, while Bergmann's rule is related to an increase or decrease in absolute body mass (volume) without necessarily changing body shape.

In this study, we use a freely available data set of postcranial linear measurements (Goldman Data set — http://web.utk.edu/ auerbach/GOLD.htm; Auerbach and Ruff 2006) in order to separate, for the first time, the relative effect of neutral demographic processes and climatic selection on the long (limb) bones and the pelvic bones of the human appendicular skeleton. The original data set has been expanded to include six additional sub-Saharan African populations in order to adequately account for the high intracontinental variability expected in sub-Saharan African populations (e.g., Henn et al. 2011; Jorde et al. 1997, 2000). The OoA demographic (population history) signature will be used as an indicator of neutral evolution, given the very distinctive pattern and clear predictions associated with it. Hence, using this model as a null hypothesis, two specific predictions can be made depending on the level of selection acting on the different anatomical regions:

(1) If phenotypic variation is largely neutral, then — in a manner similar to the human cranium - within-population postcranial variation should show a significant fit to the OoA (serial founder effect) model and exhibit no significant correlation with climate.

(2) Conversely, if climatic selection has annihilated the underlying neutral signature, then postcranial phenotypic variation will not show a significant 


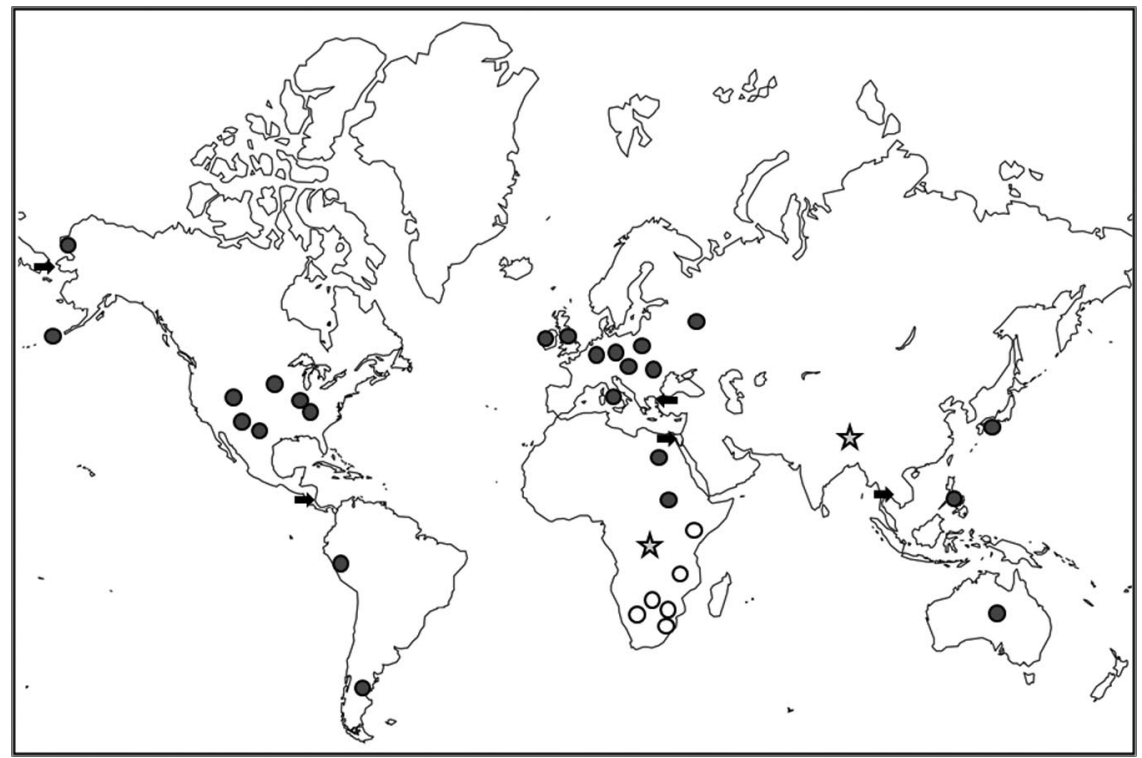

Figure 1. Distribution of the population samples from the Goldman data set (solid circles), and the newly collected African samples (open circles). Points used as starting points for calculation of geographic distances used in the analyses are represented by stars, while compulsory waypoints are indicated as black arrows.

fit to the OoA model, but will rather exhibit a significant relationship with climate.

\section{Materials and Methods}

From the original data in the Goldman data set, only populations with complete data from at least 15 individuals were selected for inclusion in the analyses (Figure 1, Table 1). In order to avoid the potentially confounding effects of sexual dimorphism, the analyses were restricted to male individuals because of the much larger sample size available. Measurements were chosen preferably from the left side, using the right side only in cases where the left presented missing data. The data set thus comprised measurements for the pelvis, femur, tibia, humerus, and radius.

In addition to the 24 population samples collated from the Goldman data set, an additional six sub-Saharan samples were added by collecting primary data (LB) housed at the National Museum of Kenya (Nairobi, Kenya) and the University of Witwatersrand (Johannesburg, South Africa) (see Table 1). These additional samples were chosen in order to maximize the geographic coverage of sub-Saharan Africans close to the putative origin as described in previous studies of molecular variation (e.g., Manica et al. 2007). The same measurements as used in the Goldman database (see Table 2) were collected on each of the five anatomical regions according to the protocol described by Auerbach and Ruff 


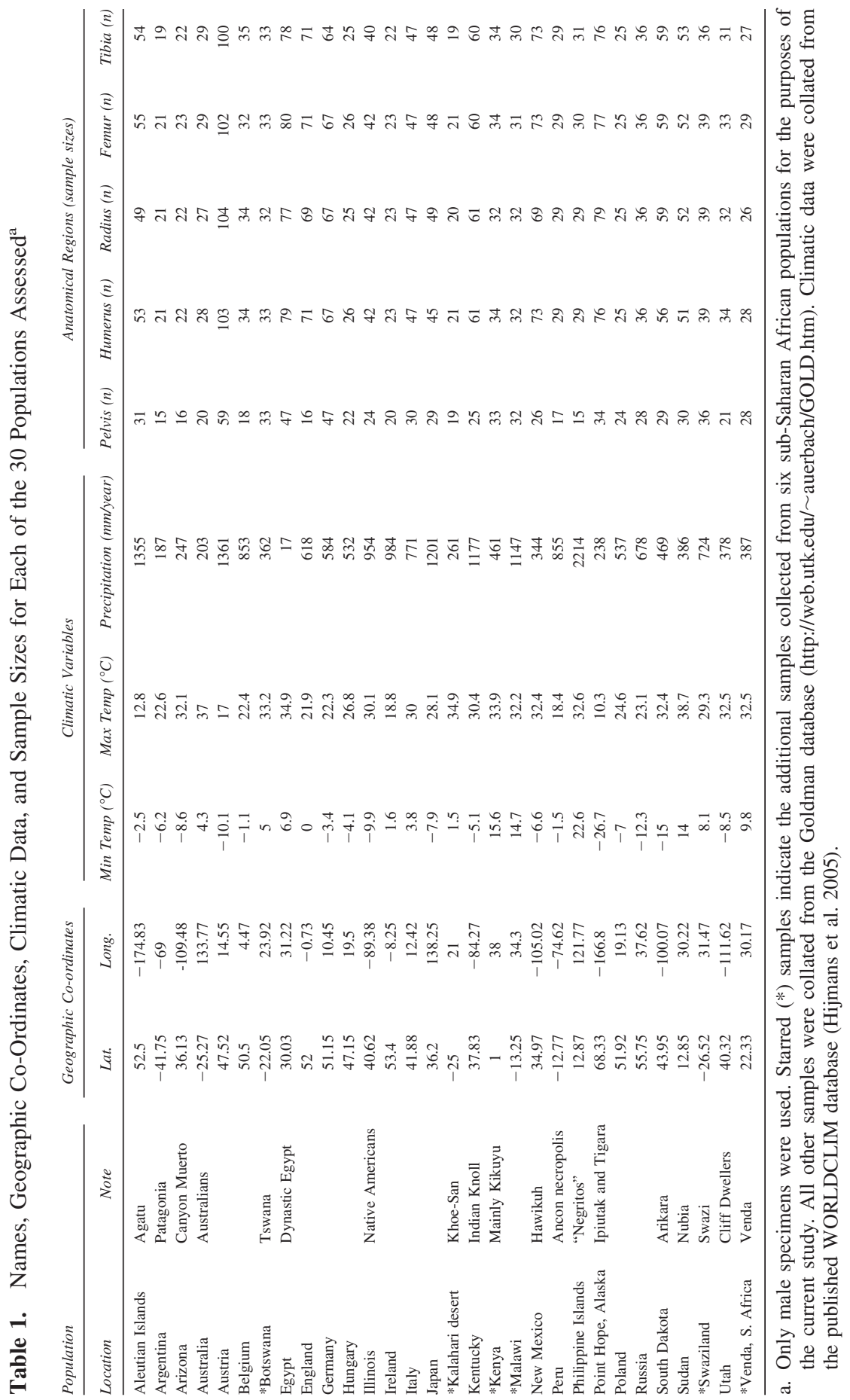


Table 2. Linear Measurements Used to Estimate Within-Population Variance for Each of the Five Anatomical Regions

Measurements

\begin{tabular}{ll}
\hline Humerus & Femur \\
- Maximum Length & - Maximum Length \\
- Epicondylar Breadth & - Bicondylar Length \\
- Head Diameter & - Epicondylar Mediolateral Breadth \\
- 50\% Diaphyseal Mediolateral Diameter & - Distal Articular (Bicondylar) Mediolateral Breadth \\
- 50\% Diaphyseal Anteroposterior Diameter & - Head Anteroposterior Diameter \\
& - 50\% Diaphyseal Mediolateral Diameter \\
Tibia & - 50\% Diaphyseal Anteroposterior Diameter \\
- Maximum Length & \\
- Plateau Mediolateral (Bicondylar) Breadth & Pelvis \\
- 50\% Diaphyseal Mediolateral Diameter & - Bi-iliac Breadth \\
- 50\% Diaphyseal Anteroposterior Diameter & - Maximum Iliac Blade Length \\
& - Maximum Acetabular Height \\
Radius & \\
- Maximum Length & \\
- 50\% Diaphyseal Mediolateral Diameter & \\
- 50\% Diaphyseal Anteroposterior Diameter & \\
\hline
\end{tabular}

(2004, 2006). Given that population within-group variances were calculated using each individual population sample (i.e., from a single observer), interobserver error is unlikely to affect the results of the analysis. Moreover, the effect of inter-observer differences was also tested by performing a post-hoc analysis of just the Goldman data set minus the new sub-Saharan samples.

All measurements (Table 2) were size-adjusted by dividing each measurement by the geometric mean of all measurements of the same bone (Jungers et al. 1995). This method equalizes the volumes of all specimens (i.e., isometrically scales each specimen to the same size) while maintaining overall shape information (Falsetti et al. 1993; Jungers et al. 1995). Individual withinpopulation variances were calculated as the average of the trace of the variance-covariance matrix, following the Relethford and Blangero (1990) model for quantitative traits. The Relethford-Blangero estimator of population genetic affinities based on quantitative traits assumes an equal and additive model of inheritance. Multivariate covariance matrices were calculated under the assumption that population phenotypic variances are proportional to genetic variances. All within-population variances were calculated under the assumption of complete heritability $h^{2}=1$ given the lack of appropriate population-specific heritability estimates for the anatomical regions under consideration here.

To test for the OoA signature, the geographic distances of each population sample from central sub-Saharan Africa (Betti et al. 2009; Manica et al. 2007) were calculated using great circle distances, based on the haversine (Sinnott 1984). In order to better approximate actual distances on the ground (i.e., limiting long-distance sea-crossings), five waypoints were imposed when calculating the distances. These geographic waypoints and their co-ordinates are listed in Table 3. In 
Table 3. Origin Points Used to Calculate Great Circle Distances and Obligatory Waypoints Imposed in This Study

\begin{tabular}{ll} 
Origins & \multicolumn{1}{c}{ Coordinates } \\
\hline Central Africa (Democratic Republic of the Congo) & $8 \mathrm{~S}, 25 \mathrm{E}$ \\
Central Asia (Lhasa, Tibet, China) & $29.63 \mathrm{~N}, 91.13 \mathrm{E}$ \\
\hline Waypoints & \\
\hline Sinai Peninsula, Egypt (any route out of Africa) & $30.07 \mathrm{~N}, 33.7 \mathrm{E}$ \\
Istanbul, Turkey (routes connecting Africa and Europe) & $41 \mathrm{~N}, 29 \mathrm{E}$ \\
Thailand (routes to Australia) & $16.13 \mathrm{~N}, 98.35 \mathrm{E}$ \\
Bering Strait (routes to the Americas) & $65.78 \mathrm{~N}, 169.97 \mathrm{~W}$ \\
Panama (routes to South America) & $13.5 \mathrm{~N}, 86.2 \mathrm{~W}$
\end{tabular}

order to compare phenotypic variability with climate, a climatic data set of average minimum and maximum temperature $\left({ }^{\circ} \mathrm{C}\right)$ for the coldest and hottest month respectively, and annual average precipitation (mm/year) was collated from WORLDCLIM (Hijmans et al. 2005), as a set of global climatic GIS layers interpolating data from approximately 15,000 weather stations distributed worldwide (Table 2). Ideally, climatic data coeval to the population samples should be used for the analyses. Variation in climatic conditions during the time span covered by our samples, however, has been quite limited. Moreover, given the global nature of our sample, small regional temporal fluctuations in temperature will be minimal compared with the global differences in temperature between widely distributed populations. Indeed, the use of modern global climatic data of this nature is in line with recent equivalent analyses of human cranial variation (e.g., Betti et al. 2009, 2010; Harvati and Weaver 2006a, 2006b; Hubbe et al. 2009; Noback et al. 2011; Roseman 2004; von Cramon-Taubadel 2009, 2011).

In order to test the predictions, we implemented a stepwise regression procedure using the "Drop1" function (http://stat.ethz.ch/R-manual/R-patched/ library/stats/html/add1.html) of the software R (R Development Core Team 2007). We started with a full linear model, in which phenotypic variance is assumed to be affected by the iterative founder events that accompanied the expansion of the species OoA, as well as by climate. This model included, as independent factors, geographic distance from Central Africa, minimum and maximum temperature, average precipitation, and all possible interactions between the three climatic variables. Starting from this model, we excluded all nonsignificant factors by backward stepwise elimination. The exclusion of single factors, sequentially, from the model was performed respecting the hierarchy of factors (interactions between factors were considered before excluding the factors themselves), and was determined by the relative increase/decrease of Akaike Information Criterion (AIC) (Akaike 1973) following the exclusion of a factor. Moreover, an ANOVA was performed at each step to confirm that the exclusion of the factor did not significantly decrease the 
Table 4. Results of the Linear Models ${ }^{\mathrm{a}}$

\begin{tabular}{llcc} 
Skeletal Region & Minimal Model & $R^{2}$ & $P$-value \\
\hline Pelvis & PhVar Dist & 0.154 & $\mathbf{0 . 0 3 2}$ \\
Humerus & n.a. & 0.214 & 0.555 \\
Tibia & PhVar Tmin & 0.163 & $\mathbf{0 . 0 2 7}$ \\
Radius & n.a. & 0.251 & 0.425 \\
Femur & PhVar Tmin & 0.261 & $\mathbf{0 . 0 0 4}$
\end{tabular}

a. Statistically significant results are in bold $(\alpha=0.05)$. PhVar $=$ Phenotypic Variance, Dist $=$ Distance from Africa, $T_{\min }=$ Minimum Temperature. In the case of the humerus and radius, no significant factors were found so the values for the full model are presented.

accuracy of the model. In cases where no significant factor was found, the results of the full model regression are presented.

\section{Results}

Table 4 and Figure 2 show the results of the stepwise regression analysis. Notably, the results of the linear models show a very different pattern for the pelvis in respect to the limb bones. Pelvic shape variance is significantly correlated with geographic distance from Africa (i.e., minimal model = PhVar Dist), following the same pattern expected under the neutral model, and in line with the previous results from genetic markers and craniodental traits. Conversely, the humerus, tibia, radius, and femur do not exhibit a fit to the geographic (OoA) model. Rather, within-population morphological diversity for both the femur and tibia significantly correlates with minimum temperature (i.e.,

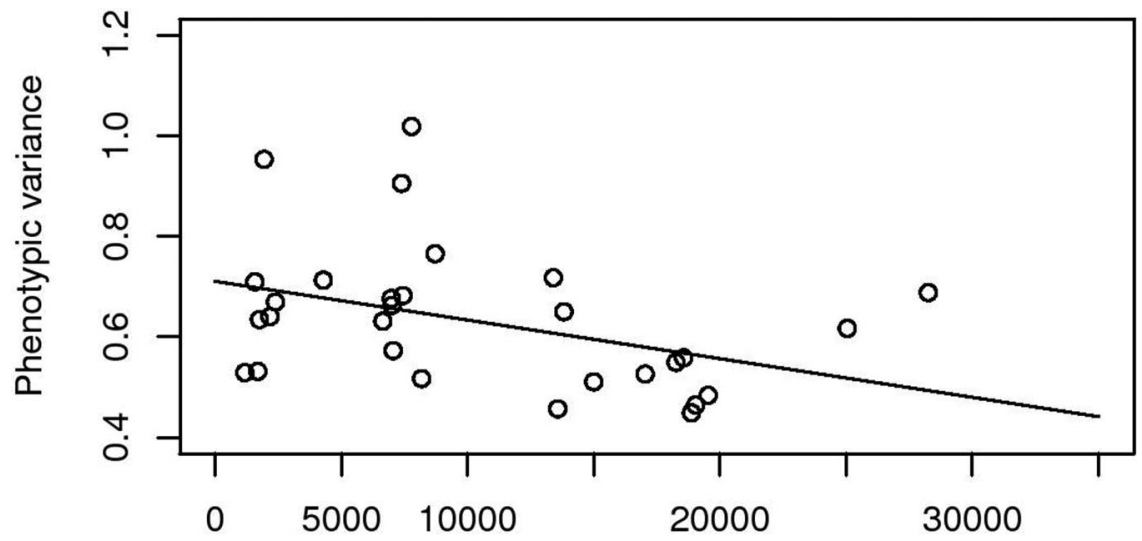

Distance from Central Africa $(\mathrm{Km})$

Figure 2. Linear regression of phenotypic within-population variance and geographic distance for the pelvis, with central Africa $(8 \mathrm{~S}, 25 \mathrm{E})$ used as point of origin $\left(\mathrm{R}^{2}=0.154, P=0.032\right)$. 


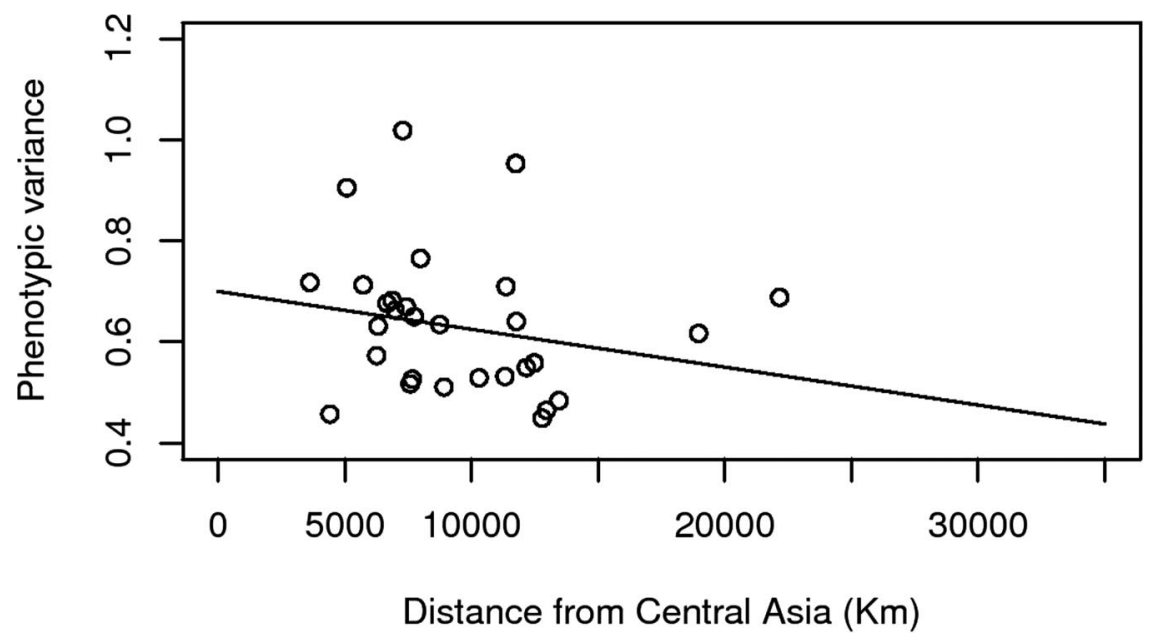

Figure 3. Linear regression of phenotypic within-population variance and geographic distance for the pelvis, with central Asia $(29.63 \mathrm{~N}, 91.13 \mathrm{E})$ used as point of origin $\left(\mathrm{R}^{2}=0.042, P=0.28\right)$.

minimal model $=$ PhVar $\sim$ Tmin). These results are consistent with the hypothesis that climatic selection has obliterated the effects of population history (i.e., OoA dispersal) in the case of these lower limb bones.

In order to further evaluate the robustness of our results, a number of post-hoc tests were undertaken. In the case of the pelvis (for comparison with the OoA model), we tested for a fit between geographic distance and a hypothetical point of origin in central Asia (see Figure 3, Table 3). No significant relationship was found $\left(\mathrm{R}^{2}=0.042 ; P=0.28\right)$. We also repeated the OoA analysis for the pelvis using only populations included in the original Goldman data set, in order to corroborate that the results were not affected by the inclusion of the additional data from sub-Saharan Africa. This analysis provided results consistent with those of our primary analysis $\left(\mathrm{R}^{2}=0.162 ; P=0.05\right)$. Additionally, we tested whether a significant relationship existed between population sample sizes for the pelvis and within-population variances; no such relationship was found $\left(\mathrm{R}^{2}=\right.$ $0.00031 ; P=0.93)$.

\section{Discussion}

An OoA fit to a serial founder effect model has previously been shown for human genetic variation (Liu et al. 2006; Prugnolle et al. 2005; Ramachandran et al. 2005), craniodental variation (Hanihara 2008; Manica et al. 2007; von Cramon-Taubadel and Lycett 2008), and even linguistic variation (Atkinson 2011). Here, we assessed whether population-level variation in post-cranial elements of the human skeleton might also fit this model.

Our results indicate a sharp difference in the way the pelvis and the limb bones reflect the neutral signature of the OoA expansion. Consistent with 
previous analyses of the cranium and dentition, pelvic shape shows a significant decrease in within-population variation with increasing distance from Africa. However, no such pattern could be found in the long bones. Rather, in the case of both the tibia and the femur, a significant relationship between populationlevel variance and minimum temperature was demonstrated. Hence, in the case of these lower limb bones, it is probable that the effects of climatic selection have obliterated the effects of population history (i.e., our dispersal OoA).

These results also indicate that climatic selection has had a stronger effect on the lower limb in respect to the upper limb, at least in terms of shape effects. One possible explanation could be that differing population activity patterns, and the subsequent remodeling responses of osseous tissue at a population level, may feasibly have contributed to erasing evidence of climatic selection on the upper limb that could otherwise have been present (e.g., Currey 1984; Ruff 1999; Stock) and Pfeiffer 2001; Stock 2006). Such factors could also, of course, provide an additional reason (i.e., to selection) as to why the effects of demographic history are not as readily detected in the long bones as they are in the pelvis.

The OoA signature appears less clear on the pelvis than on the cranium, where it has been shown that as much as $19-26 \%$ of within-population levels of variation may be explained by distance from sub-Saharan Africa (e.g., von Cramon-Taubadel and Lycett 2008). This may be due to methodological differences, such as the far lower number of pelvic measurements used; however, we cannot rule out the possibility that such differences might also reflect differing microevolutionary histories for the cranium versus the pelvis (i.e., they have been affected differentially by the evolutionary forces of drift, migration, selection, etc.). Indeed, while our results show a clear difference in the relative neutrality of the pelvis compared against the limb bones, our results should not be interpreted as implying that no climatic (or other) selection has acted on the human pelvis in different populations and regions, merely that the extent of such selection has not obliterated entirely the effects of population history. Moreover, we cannot assess the impact of directional versus stabilizing selection on the post-cranium, as directional selection can increase differences between populations, without necessarily affecting within-population diversity.

The results of our analyses are particularly striking when we consider that two out of the three pelvic measurements have previously been suggested to be under climatic selection. The diameter of the acetabulum varies accordingly to the femoral head diameter (Ruff 2010), which in turn relates closely to body mass (e.g., Grine et al. 1995; McHenry 1992; Ruff et al. 1991). According to Bergmann's (1847) rule, body mass should be higher in cold climates in respect to warm regions, and we could therefore expect femoral head diameter, and therefore acetabular diameter, to be affected by climate in a similar way. Bergmann's and Allen's rule have also been used to explain the global pattern of bi-iliac breath, with larger hips and trunks in arctic regions and narrower bodies in tropical populations (Ruff 1994). However, it is worth reiterating that our 
analyses used data scaled for the effects of overall isometric size (i.e., volumes were equalized). Hence, while raw pelvic dimensions may have been affected by selection for overall isometric size (i.e., according to Bergmann's rule), our results suggest that the effects of climate on pelvic shape variation have not been prevalent.

One of the limitations of our analysis is that it only included male specimens. An important future extension of this study is, therefore, to determine if the neutral pattern of variation we have found in males holds true in global patterns of human female pelvic morphology. This is important to determine, given the fundamental functional involvement of the pelvis in parturition, and hence potential obstetric constraints on morphological variation (e.g., Rosenberg and Trevathan 1997; Tague 1995; Weaver and Hublin 2009).

Our finding that human pelvic variation exhibits the neutral effects of demographic history, suggests that consideration of this skeletal element might be used to shed light on factors associated with population history, just as the human cranium has done (Roseman and Weaver 2007; von Cramon-Taubadel and Weaver 2009). Moreover, its potential role as an indicator of neutral demographic history may also be of import with regard to interpreting population history in fossil hominins, especially given that the available fossil sample of hominin pelvic remains has improved in recent years (Kibii et al. 2011; Lovejoy et al. 2009; Simpson et al. 2008).

Acknowledgments We are grateful to Brendon Billings of the Medical School of the University of Witwatersrand and Dr. Ogeto Mwebi of the National Museum of Kenya for allowing access to collections and general assistance. We are also especially grateful to Dr. Benjamin Auerbach for generously making his data freely available. We thank Franz Manni and three anonymous reviewers for constructive comments. This study was funded by Sigma Xi, The Wenner-Gren Foundation for Anthropological Research, and a University of Kent Research Scholarship.

Received 2 November 2011; revision accepted for publication 8 February 2012.

\section{Literature Cited}

Akaike, H. 1973. Information theory and an extension of the maximum likelihood principle. In Second International Symposium on Information Theory, B. N. Petrov and F. Csaki, eds. Budapest: Academiai Kiado, 267-281.

Allen, J. A. 1877. The influence of physical conditions in the genesis of species. Rad. Rev. $1: 108-140$.

Atkinson, Q. D. 2011. Phonemic diversity supports a serial founder effect model of language expansion from Africa. Science 332:346-349.

Auerbach, B. M., and C. B. Ruff. 2004. Human body mass estimation: a comparison of "morphometric" and "mechanical" methods. Am. J. Phys. Anthropol. 125:331-342.

Auerbach, B. M., and C. B. Ruff. 2006. Limb bone bilateral asymmetry: variability and commonality among modern humans. J. Hum. Evol. 50:203-218.

Beals, K. L. 1972. Head form and climatic stress. Am. J. Phys. Anthropol. 37:85-92. 
Beals, K. L., C. L. Smith, and S. M. Dodd. 1983. Climate and the evolution of brachycephalization. Am. J. Phys. Anthropol. 62:425-437.

Beals, K. L., C. L. Smith, and S. M. Dodd. 1984. Brain size, cranial morphology, climate, and time machines. Curr. Anthropol. 25:301-330.

Bergmann, C. 1847. Uber die verhaltniesse der warmeokonomie der thiere zu ihrer grosse. Gotteningen Studien. 1:595-708.

Betti, L., F. Balloux, W. Amos et al. 2009. Ancient demography, not climate, explains withinpopulation phenotypic diversity in humans. Proc. R. Soc. B. 276:809-814.

Betti, L., F. Balloux, T. Hanihara et al. 2010. The relative role of drift and selection in shaping the human skull. Am. J. Phys. Anthropol. 141:76-82.

Cann, R. L., M. Stoneking, and A. C. Wilson 1987. Mitochondrial DNA and human evolution. Nature 325:31-36.

Currat, M., and L. Excoffier. 2011. Strong reproductive isolation between humans and Neanderthals inferred from observed patterns of introgression. Proc. Natl. Acad. Sci.. 108:15129-15134.

Currey, J. 1984. The Mechanical Adaptations of Bones. Princeton: Princeton University Press.

Falsetti, A., W. Jungers, and T. Colle. 1993. Morphometrics of the callitrichid forelimb: A case study in size and shape. Int. J. Primatol. 14:551-572.

Franciscus, R. G., and J. C. Long. 1991. Variation in human nasal height and breadth. Am. J. Phys. Anthropol. 85:419-427.

Ghirotto, S., F. Tassi, A. Benazzo et al. 2011a. No evidence of Neandertal admixture in the mitochondrial genomes of early European modern humans and contemporary Europeans. Am. J. Phys. Anthropol. 146:242-252.

Ghirotto, S., L. Penso-Dolfin, and G. Barbujani. 2011b. Genomic evidence for an African expansion of anatomically modern humans by a southern route. Hum. Biol. 83:477-489.

González-José, R., S. L. Dahinten, M. A. Luis et al. 2001. Craniometric variation and the settlement of the Americas: testing hypotheses by means of R-matrix and matrix correlation analyses. Am. J. Phys. Anthropol. 116:154-165.

González-José, R., C. García-Moro, S. Dahinten et al. 2002. Origin of Fueguian-Patagonians: an approach to population history and structure using $\mathrm{R}$ matrix and matrix permutation methods. Am. J. Hum. Biol. 14:308-320.

González-José, R., N. Martínez-Abadías, A. González-Martín et al. 2007. Detection of a population replacement at the Classic-Postclassic transition in Mexico. Proc. R. Soc. B: Biol. Sci. 274:681-688.

Green, R. E., J. Krause, A. W. Briggs et al. 2010. A draft sequence of the Neandertal genome. Science 328:710-722.

Grine, F. E., W. L. Jungers, P. V. Tobias et al. 1995. Fossil Homo femur from Berg Aukas, northern Namibia. Am. J. Phys. Anthropol. 97:151-185.

Hanihara, T. 2008. Morphological variation of major human populations based on nonmetric dental traits. Am. J. Phys. Anthropol. 136:169-182.

Harvati, K., and T. D. Weaver. 2006a. Reliability of Cranial Morphology in Reconstructing Neanderthal Phylogeny. In Neanderthals Revisited: New Approaches and Perspectives, K. Harvati and T. L. Harrison, eds. Dordrecht, Netherlands: Springer, 239-254.

Harvati, K., and T. D. Weaver 2006b. Human cranial anatomy and the differential preservation of population history and climate signatures. Anat. Rec. Part A 288A:1225-1233.

Henn, B. M., C. R. Gignoux, M. Jobin et al. 2011. Hunter-gather genomic diversity suggests a southern African origin for modern humans. Proc. Natl. Acad. Sci. USA, in press.

Hijmans, R. J., S. E. Cameron, J. L. Parra et al. 2005. Very high resolution interpolated climate surfaces for global land areas. Int. J. Climatol. 25:1965-1978.

Hodgson, J. A., C. M. Bergey, and T. R. Disotell. 2010. Neandertal genome: the ins and outs of African genetic diversity. Curr. Biol. 20:R517-R519.

Holliday, T. W. 1997. Body proportions in Late Pleistocene Europe and modern human origins. $J$. Hum. Evol. 32:423-447. 
Holliday, T. W., and C. E. Hilton. 2010. Body proportions of circumpolar peoples as evidenced from skeletal data: Ipiutak and Tigara (Point Hope) versus Kodiak Island Inuit. Am. J. Phys. Anthropol. 142:287-302.

Hubbe, M., W. A. Neves, and K. Harvati. 2010. Testing evolutionary and dispersion scenarios for the settlement of the New World. PLOS ONE 5:e11105.

Hubbe, M., K. Harvati, and W. Neves. 2011. Paleoamerican morphology in the context of European and East Asian late Pleistocene variation: Implications for human dispersion into the new world. Am. J. Phys. Anthropol. 144:442-453.

Ingman, M., H. Kaessmann, S. Pääbo et al. 2000. Mitochondrial genome variation and the origin of modern humans. Nature 408:708-713.

Jorde, L. B., A. Rogers, M. J. Bamshad et al. 1997. Microsatellite diversity and the demographic history of modern humans. Proc. Natl. Acad. Sci. USA 94:3100-3103.

Jorde, L. B., W. S. Watkins, M. J. Bamshad et al. 2000. The distribution of human genetic diversity: a comparison of mitochondrial, autosomal, and Y-chromosome data. Am. J. Hum. Genet. 66:979-988.

Jungers, W. L., A. B. Falsetti, and C. E. Wall. 1995. Shape, relative size, and size adjustments in morphometrics. Yearbook of Phys. Anthropol. 38:137-161.

Kibii, J. M., S. E. Churchill, P. Schmid et al. 2011. A partial pelvis of Australopithecus sediba. Science 333:1407-1411.

Liu, H., F. Prugnolle, A. Manica et al. 2006. A geographically explicit genetic model of worldwide human-settlement history. Am. J. Hum. Genet. 79:230-237.

Lovejoy, C. O., G. Suwa, L. Spurlock et al. 2009. The pelvis and femur of Ardipithecus ramidus: The emergence of upright walking. Science 326:71e71-71e76.

Manica, A., W. Amos, F. Balloux et al. 2007. The effect of ancient population bottlenecks on human phenotypic variation. Nature 448:346-349.

McHenry, H. M. 1992. Body size and proportions in early hominids. Am. J. Phys. Anthropol. 87:407-431.

Noback, M. L., K. Harvati, and F. Spoor. 2011. Climate-related variation of the human nasal cavity. Am. J. Phys. Anthropol. 145:599-614.

Pinhasi, R., and N. von Cramon-Taubadel 2009. Craniometric data supports demic diffusion model for the spread of agriculture into Europe. PLoS ONE 4:e6747.

Prugnolle, F., A. Manica, and F. Balloux. 2005. Geography predicts neutral genetic diversity of human populations. Curr. Biol. 15:R159-R160.

$\mathrm{R}$ Development Core Team 2011. R: A Language and Environment for Statistical Computing. Vienna, R Foundation for Statistical Computing.

Ramachandran, S., O. Deshpande, C. Roseman et al. 2005. Support from the relationship of genetic and geographic distance in human populations for a serial founder effect originating in Africa. Proc. Natl. Acad. Sci. USA 102:15942-15947.

Rasmussen, M., X. Guo, Y. Wang et al. 2011. An aboriginal Australian genome reveals separate human dispersals into Asia. Science 334:94-98.

Relethford, J. H. 1994. Craniometric variation among modern human populations. Am. J. Phys. Anthropol. 95:53-62.

Relethford, J. H. 2002. Apportionment of global human genetic diversity based on craniometrics and skin color. Am. J. Phys. Anthropol. 118:393-398.

Relethford, J. H. 2004. Global patterns of isolation by distance based on genetic and morphological data. Hum. Biol. 76:499-513.

Relethford, J. H., and J. Blangero. 1990. Detection of differential gene flow from patterns of quantitative variation. Hum. Biol. 62:5-25.

Roseman, C. C. 2004. Detecting interregionally diversifying natural selection on modern human cranial form by using matched molecular and morphometric data. Proc. Natl. Acad. Sci. USA 101:12824-12829.

Roseman, C. C., and T. D. Weaver. 2004. Multivariate apportionment of global human craniometric diversity. Am. J. Phys. Anthropol. 125:257-263. 


\section{2 / BETTI ET AL.}

Roseman, C. C., and T. D. Weaver. 2007. Molecules versus morphology? Not for the human cranium. Bioessays 29:1185-1188.

Rosenberg, K., and W. Trevathan. 1995. Bipedalism and human birth: The obstetrical dilemma revisited. Evol. Anthropol.: Issues, News, and Rev. 4:161-168.

Ruff, C. B. 1993. Climatic adaptation and hominid evolution: The thermoregulatory imperative. Evol. Anthropol. 2:53-60.

Ruff, C. B. 1994. Morphological adaptation to climate in modern and fossil hominids. Am. J. Phys. Anthropol. 37:65-107.

Ruff, C. B. 1999. Skeletal structure and behavioral patterns of prehistoric Great Basin populations.

In Understanding Prehistoric Lifeways in the Great Basin Wetlands: Bioarchaeological Reconstruction and Interpretation, B. E. Hemphill and C. S. Larsen, eds. Salt Lake City: University of Utah Press, 290-320.

Ruff, C. B. 2010. Body size and body shape in early hominins-implications of the Gona Pelvis. $J$. Hum. Evol. 58:166-178.

Ruff, C. B., W. W. Scott, and A. Y. C. Liu. 1991. Articular and diaphyseal remodeling of the proximal femur with changes in body mass in adults. Am. J. Phys. Anthropol. 86:397-413.

Simpson, S. W., J. Quade, N. E. Levin et al. 2008. A female Homo erectus pelvis from Gona, Ethiopia. Science 322:1089-1092.

Sinnott, R. W. 1984. Virtues of the haversine. Sky and Telescope 68:158.

Smith, H. F. 2009. Which cranial regions reflect molecular distances reliably in humans? Evidence from three-dimensional morphology. Am. J. Hum. Biol. 21:36-47.

Smith, H. F. 2011. The role of genetic drift in shaping modern human cranial evolution: a test using microevolutionary modeling. Int. J. Evol. Biol. 145262:1-11.

Stock, J. T. 2006. Hunter-gatherer postcranial robusticity relative to patterns of mobility, climatic adaptation, and selection for tissue economy. Am. J. Phys. Anthropol. 131:194-204.

Stock, J. T., and S. Pfeiffer. 2001. Linking structural variability in long bone diaphyses to habitual behaviors: foragers from the southern African Later Stone Age and the Andaman Islands. Am. J. Phys. Anthropol. 115:337-348.

Stoneking, M., and J. Krause. 2011. Learning about human population history from ancient and modern genomes. Nat. Rev. Genet. 12:603-614.

Strauss, A., and M. Hubbe. 2010. Craniometric similarities within and between human populations in comparison with neutral genetic data. Hum. Biol. 82:315-330.

Tague, T. G. 1995. Variation in pelvic size between males and females in nonhuman anthropoids. Am. J. Phys. Anthropol. 213-233.

Thomson, R., J. K. Pritchard, P. Shen et al. 2000. Recent common ancestry of human Y chromosomes: Evidence from DNA sequence data. Proc. Natl. Acad. Sci. USA 97:7360-7365.

von Cramon-Taubadel, N. 2009a. Congruence of individual cranial bone morphology and neutral molecular affinity patterns in modern humans. Am. J. Phys. Anthropol. 140:205-215.

von Cramon-Taubadel, N. 2009b. Revisiting the homoiology hypothesis: The impact of phenotypic plasticity on the reconstruction of human population history from craniometric data. J. Hum. Evol. 57:179-190.

von Cramon-Taubadel, N. 2011. The relative efficacy of functional and developmental cranial modules for reconstructing global human population history. Am. J. Phys. Anthropol. 146:83-93.

von Cramon-Taubadel, N., and S. J. Lycett. 2008. Human cranial variation fits iterative founder effect model with African origin. Am. J. Phys. Anthropol. 136:108-113.

von Cramon-Taubadel, N., and T. D. Weaver. 2009. Insights from a quantitative genetic approach to human morphological evolution. Evol. Anthropol. 18:237-240.

von Cramon-Taubadel, N., and R. Pinhasi. 2011. Craniometric data support a mosaic model of demic and cultural Neolithic diffusion to outlying regions of Europe. Proc. R. Soc. B. 278:2874-2880.

Weaver, T. D., and J.-J. Hublin. 2009. Neandertal birth canal shape and the evolution of human childbirth. Proc. Natl. Acad. Sci. USA 106:8151-8156. 